\title{
Cytokine-induced killer cell therapy for the treatment of primary hepatocellular carcinoma subsequent to liver transplantation: A case report
}

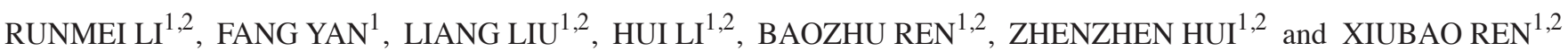 \\ ${ }^{1}$ Department of Immunology, National Clinical Research Center of Cancer; ${ }^{2}$ Biotherapy Center, Key Laboratory of Cancer \\ Immunology and Biotherapy, Tianjin Medical University Cancer Institute \& Hospital, Tianjin 300060, P.R. China
}

Received January 26, 2015; Accepted November 30, 2015

DOI: $10.3892 / 01.2016 .4109$

\begin{abstract}
Liver cancer, of which the most common form is hepatocellular carcinoma (HCC), is one of the most lethal cancers worldwide. Immunotherapy based on the direct attack of tumor cells and the stimulation of an antitumor immune response may represent a novel strategy to control HCC recurrence and metastasis. The present study reports the case of a patient with HCC, and describes the safety and feasibility of successful administration with a mass of autologous activated $\mathrm{T}$ cells on numerous occasions subsequent to liver transplantation (LT), in order to kill the residual tumor cells and stimulate the immune system. A large number of infused activated $\mathrm{T}$ cells may pose a potential risk to the allograft. However, no acute or delayed adverse effects of cytokine-induced killer cell (CIK) therapy, or other symptoms of secondary acute host-versus-graft disease (HVGD), were observed. These observations demonstrate the relatively low toxicity of CIK infusion to a patient that has undergone LT, and more importantly, they demonstrate the feasibility of this immunotherapy for the patient, following successful LT.
\end{abstract}

Correspondence to: Professor Xiubao Ren, Biotherapy Center, Key Laboratory of Cancer Immunology and Biotherapy, Tianjin Medical University Cancer Institute \& Hospital, 24 Binshui Road, Tianjin 300060, P.R. China

E-mail: rwziyi@yahoo.com

Abbreviations: LT, liver transplantation; CIK, cytokine-induced killer cell; HCC, hepatocellular carcinoma; HVGD, host-versus-graft disease; TBIL, total bilirubin; DBIL, direct bilirubin; ALT, alanine aminotransferase; AST, aspartate aminotransferase

Key words: liver transplantation, cytokine-induced killer cell, host-versus-graft disease, adoptive immunotherapy, hepatocellular carcinoma

\section{Introduction}

Primary hepatocellular carcinoma (HCC) is one of the most common malignant tumors that result in a high mortality rate. Liver transplantation (LT) is the treatment of choice for a select group of patients with early-stage unresectable HCC (1). Studies of tumoral behavior in the setting of transplantation have also identified additional potential predictors of outcome, including tumor differentiation, lobar distribution, serum $\alpha$-fetoprotein (AFP) level, serum alkaline phosphatase, tumor volume, etiology of liver disease and molecular markers, such as loss of heterozygosity and gene expression $(2,3)$. However, there is a high frequency of tumor recurrence following LT. In these patients, tumor recurrence usually occurs within a year of LT, and the survival time is several months (median, 12.2 months) at the time of relapse (4). Currently, several factors have been indicated to contribute to HCC recurrence. Tumor cells are occasionally not completely removed by total hepatectomy, so recurrence may originate from residual tumors. In addition, tumor cells may persist in a dormant state for a long time prior to the induction of clinical metastases, hematogenous spread, extrahepatic metastases and other sources of tumor recurrence, since small metastatic lesions may easily be missed by computed tomography (CT) scans, magnetic resonance imaging and various radiographic examinations $(4,5)$. Therefore, an effective anti-cancer therapy following the surgical removal of hepatic malignancy is required.

Increasing evidence indicates that adoptive immunotherapy may decrease the recurrence and metastasis rates of solid malignant tumors (6-9). Autologous activated immune cells, including cytokine-induced killer (CIK) cells, are a unique population of cytotoxic $\mathrm{T}$ lymphocytes that express natural killer and T-cell markers, and may be generated from peripheral blood mononuclear cells treated with interferon (IFN)- $\gamma$, anti-cluster of differentiation (CD)3 monoclonal antibody, and interleukin (IL)-2. These CIK cells have demonstrated increased proliferative and cytotoxic activities against autologous and allogeneic malignant cells $(10,11)$. Previous studies also report that adoptive immunotherapy using autologous CIK cells may decrease tumor recurrence and metastasis in postsurgical and advanced liver cancer patients $(12,13)$. Therefore, autologous CIK cells may be an effective therapeutic 
method for patients that are diagnosed with HCC subsequent to LT.

The immune system of patients with LT may develop elaborate and effective mechanisms to combat foreign agents. These mechanisms are involved in the rejection of transplanted organs, which are recognized as foreign substances by the recipient's immune system. Liver allograft rejection is mediated by a primary response of $\mathrm{T}$ lymphocytes, followed by the infiltration of the graft and mixed inflammatory reactions. The proliferation of mononuclear leukocytes inside the allograft is a prominent feature of acute and chronic rejection (13). Therefore, a large number of infused activated $\mathrm{T}$ cells may pose a potential risk to the allograft.

The present study reports the treatment of a patient that was diagnosed with primary HCC following LT, using a CIK cell therapy that was generated in the current study. To the best of our knowledge, the present study is the first case report to demonstrate the feasibility and relatively low toxicity of the program. Written informed consent was obtained from the patient's family.

\section{Case report}

A 46-year-old male patient with a history of hepatitis B for $>10$ years was diagnosed with $\mathrm{HCC}$ based on typical imaging findings and elevated serum AFP levels (645 $\mu \mathrm{g} / \mathrm{l}$; normal range, $<25 \mu \mathrm{g} / \mathrm{l}$ ) in July 2010. A routine CT scan revealed a $8.5 \times 7.3 \mathrm{~cm}$ mass in the right lobe of the liver. The patient was admitted to the transplant ward of the First Central Hospital (Tianjin, China). The patient underwent LT in August 2010. Following surgery, the patient received oral immunosuppressive and liver protection treatment. The immunosuppressive treatment consisted of tacrolimus (FK506; 4 mg twice a day), methylprednisolone (15 mg daily) and mycophenolate mofetil ( $0.75 \mathrm{~g}$ twice a day). The post-operative blood levels of FK506 ranged between 3.0 and $10.9 \mathrm{ng} / \mathrm{ml}$. The examinations revealed that no acute adverse event had occurred. The liver enzymes and total bilirubin levels of the patient did not change significantly following the immunossuppressive treatment compared with the levels prior to surgery, which indicates that the transplanted liver demonstrated normal function. Furthermore, no evidence of abnormality was indicated by the liver ultrasound examination.

One month after surgery, in September 2010, the patient was admitted in Tianjin Cancer Hospital (Tianjin, China). Here, the patient received 4 cycles of treatment with CIK cells at an interval of 1 month subsequent to LT (Fig. 1). For each treatment, the patient was treated with 2 intravenous infusions of $>5 \times 10^{9} \mathrm{CIK}$ cells at 1 -day intervals. During and subsequent to the CIK cell transfusion, no infusion-associated toxicity or secondary acute host-versus-graft disease (HVGD) occurred. The most common adverse events reported following the infusions were chill, fever, headache, nausea and vomiting. The patient experienced a slight fever subsequent to 3 out of the 4 infusions. The fever was treated with Brufen $(5 \mathrm{mg} / \mathrm{kg}$, every 4-6 $\mathrm{h}$ until the patient's temperature returned to normal levels). No serious side effects were indicated according to the National Cancer Institute-Common Terminology Criteria for Adverse Events (http://evs.nci.nih.gov/ftp1/CTCAE/About. html). The clinical examinations for liver failure, such as

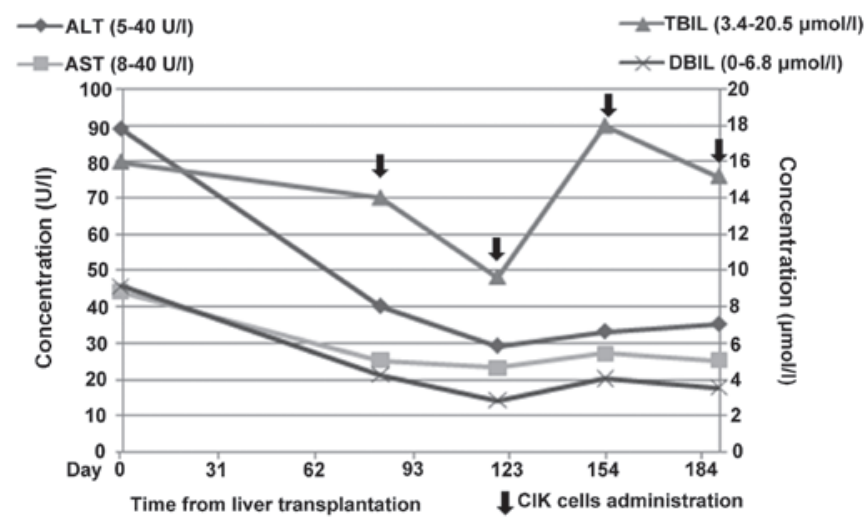

Figure 1. Clinical course of disease and the liver function tests. The X-axis shows the days from transplantation. TBIL, total bilirubin; DBIL, direct bilirubin; ALT, alanine aminotransferase; AST, aspartate aminotransferase; CIK, cytokine-induced killer.

blood tests, liver ultrasounds and CT examinations, were performed to examine for HVGD. The functional indicators of the transplanted liver were the liver volume, bile secretion, liver enzymes and total bilirubin. It was found that the blood levels of liver enzymes, including aspartate aminotransferase, alanine aminotransferase, $\gamma$-glutamyl transferase, total bilirubin and direct bilirubin, did not change significantly (Fig. 1; Table I). No increased liver volume was indicated upon quantification with ultrasound or CT examination. Furthermore, no clinical responses, such as tiredness, fever and hepatic or gastrointestinal symptoms, were observed.

The CIK cells were prepared as described in previous studies $(5,14,15)$. Briefly, peripheral blood mononuclear cells were collected from the patient using a Cobe Spectra Apheresis System (CaridianBCT, Lakewood, CO, USA) and cultured in Invitrogen AIM-V medium (Thermo Fisher Scientific, Inc., Waltham, MA, USA), containing $50 \mathrm{ng} / \mathrm{ml}$ anti-CD3 antibody (mouse anti-human, clone OKT3; cat. no. 16-0037-85; eBioscience, Inc., San Diego, CA, USA) to stimulate CIK cell growth, $100 \mathrm{U} / \mathrm{ml}$ recombinant human IL-1 $\alpha$ (eBioscience) and 1,000 U/ml recombinant human IFN- $\gamma$ (Peprotech, Rocky Hill, NJ, USA) at $37^{\circ} \mathrm{C}$ with $5 \% \mathrm{CO}_{2}$ for $24 \mathrm{~h}$. Then, $300 \mathrm{U} / \mathrm{ml}$ recombinant human IL-2 (Beijing SL Pharmaceutical Co.,Ltd., Beijing, China) was added to the media. Fresh medium containing IL-2 $(300 \mathrm{U} / \mathrm{ml})$ and IFN- $\gamma(1,000 \mathrm{U} / \mathrm{ml})$ was added to the culture media every 5 days. The CIK cells were harvested and analyzed for phenotype and cytotoxicity subsequent to 14 days of culture.

The phenotypic analysis of the prepared cells prior to culture and subsequent to 14 days of culture demonstrated the expansion of $\mathrm{CD}^{+} / \mathrm{CD} 56^{+}$cells. The mean percentages of the $\mathrm{CD}^{+}, \mathrm{CD}^{+} / \mathrm{CD}^{+}, \mathrm{CD}^{+} / \mathrm{CD}^{+}$and $\mathrm{CD}^{+} / \mathrm{CD}^{+} 6^{+}$ cell subsets were $48.41 \pm 6.19,28.07 \pm 4.76,19.00 \pm 5.54$ and $3.65 \pm 1.41 \%$, respectively, prior to culture and $97.35 \pm 2.19$, $20.40 \pm 7.50,72.85 \pm 7.00$ and $35.00 \pm 9.90 \%$, respectively, subsequent to culture. All P-values were $<0.05$ (Fig. 2). The in vitro cytotoxicity of the CIK preparations was analyzed at the end of the culture period. The CIK cells were mixed with K562 cells at effector-to-target ratios of 40:1, 20:1 and 10:1. The mean values of cytotoxicity of these CIK cell ratios against the K562 cells were $35.00 \pm 9.90,22.10 \pm 9.76$ 
Table I. Liver function examination.

\begin{tabular}{|c|c|c|c|c|c|c|}
\hline $\begin{array}{l}\text { Indicator } \\
\text { (normal range) }\end{array}$ & $\begin{array}{l}\text { Before } \\
\text { transplant }\end{array}$ & $\begin{array}{c}\text { After } \\
\text { transplant }\end{array}$ & $\begin{array}{l}\text { After } \\
\text { CIK-1 }\end{array}$ & $\begin{array}{l}\text { After } \\
\text { CIK-2 }\end{array}$ & $\begin{array}{c}\text { After } \\
\text { CIK-3 }\end{array}$ & $\begin{array}{l}\text { After } \\
\text { CIK-4 }\end{array}$ \\
\hline ALT, U/1 (5-40) & 48 & 89 & 40 & 29 & 33 & 35 \\
\hline AST, U/1 (8-40) & 62 & 44 & 25 & 23 & 27 & 25 \\
\hline ALP, U/1 (40-150) & 177 & 218 & 68 & 48 & 59 & 51 \\
\hline GGT, U/1 (11-50) & 232 & 312 & 73 & 56 & 63 & 59 \\
\hline TBIL, $\mu \mathrm{mol} / 1$ (3.4-20.5) & 15.8 & 16.0 & 14.0 & 9.6 & 18.0 & 15.2 \\
\hline DBIL,$\mu \mathrm{mol} / \mathrm{l}(0-6.8)$ & 6.0 & 9.1 & 4.2 & 2.8 & 4.0 & 3.5 \\
\hline LDH, U/1 (109-245) & 170 & 155 & - & - & - & - \\
\hline ALB, g/l (35-55) & 35 & 38 & 48.8 & 46.2 & 48.2 & 46.1 \\
\hline TBA, g/l (60-83) & 70.0 & 67.0 & 76.6 & 70.0 & 73.8 & 71.7 \\
\hline
\end{tabular}

CIK, cytokine-induced killer cell; ALT, alanine aminotransferase; AST, aspartate aminotransferase; ALP, Alkaline phosphatase; GGT, $\gamma$-glutamyl transferase; TBIL, total bilirubin; DBIL, direct bilirubin; LDH, lactate dehydrogenase; ALB, albumin; TBA, total bile acid.

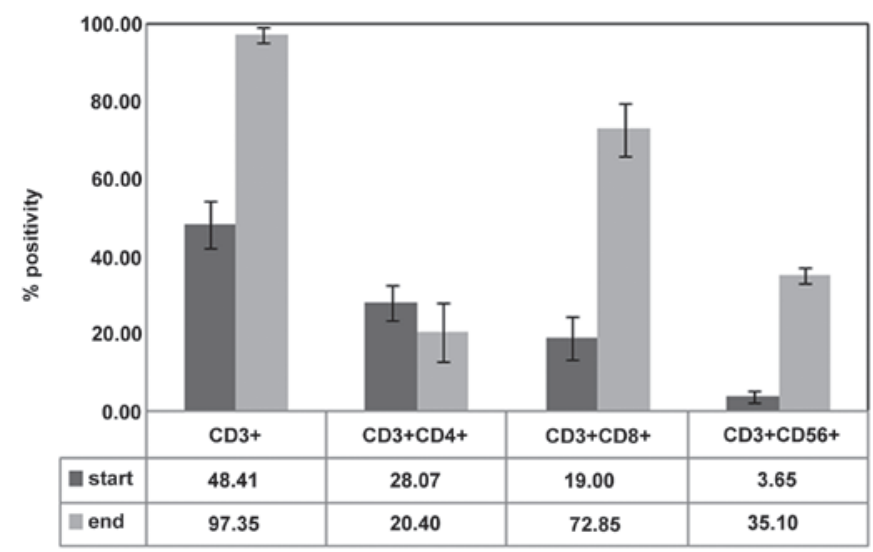

Figure 2. Phenotype analysis of CIK cell cultures. The percentage distribution of $\mathrm{CD}^{+}, \mathrm{CD}^{+} / \mathrm{CD}^{+}, \mathrm{CD}^{+} / \mathrm{CD}^{+}$and $\mathrm{CD} 3^{+} / \mathrm{CD}^{2} 6^{+}$cells obtained at the start and the end of the CIK cell cultures is shown. CIK, cytokine-induced killer; CD, cluster of differentiation.

and $14.50 \pm 9.76 \%$, respectively. All products were free of bacterial and fungal contamination, free of Mycoplasma and contained $<5 \mathrm{EU} / \mathrm{ml}$ endotoxin. The patient succumbed to the disesase in November 2013.

\section{Discussion}

To the best of our knowledge, the present study is the first to report adoptive cell transfer in a post-LT patient with HCC. In the current study, large numbers of CIK cells were produced in a 2-week time period and safely administered to a patient that underwent LT. In the case of infusion-associated toxicity or secondary acute HVGD, no additional CIK infusions would be administered. In all patients, after a minimum of 28 days, additional CIK infusions may be performed at the same time interval and up to the best clinical response, emergence of toxicity or occurrence of HVGD. The present study has demonstrated the feasibility and relatively low toxicity of the program.

CIK cells are ex vivo-expanded T lymphocytes that express natural killer and T-cell markers. Expanded cells induce the non-major histocompatibility complex-restricted lysis of tumor cells or allografts (6-9). The adverse effects of intravenous infusion of autologous CIK cells and the status of the donor's liver following the infusion of large numbers of lymphocytes are the major concerns of CIK therapy subsequent to LT in the present study. Whether CIK cells trigger the rejection of the donated liver has been a growing concern. However, no serious CIK-associated adverse effects were observed in the present patient. Certain slight adverse effects may occur following symptomatic treatment, but the clinical indicators of rejective responses were normal in the current patient.

Immunosuppressive medical treatments that are directed against T cells, including FK506 and cyclosporin A (CsA), inhibit T-cell responses (16). The present patient was treated with FK506 during CIK cell therapy to investigate how immunosuppressive drugs may affect CIK cell therapy. Certain previous studies have reported that CIK cells contain cytolytic granules that exhibit perforin and granzyme activity that are released into the extracellular space upon binding with susceptible target cells or following the cross-linking of CD3 with an anti-CD3 monoclonal antibody adhered to plastic (17-20). The use of immunosuppressive drugs, such as CsA and FK506, prevented the degranulation of CIK cells that is induced by CD3-TCR stimulation; however, the drugs were unable to block the cytotoxicity that was triggered by the interaction with tumor targets. In addition, the degranulation induced by target cells was unaffected by CsA and FK506 (6-16,21). Therefore, the use of immunosuppressive drugs may not affect the efficacy of CIK. The prepared CIK cells in the present study remained effective against liver cancer cells. Therefore, the present study demonstrates that additional patients are required to assess the relatively low toxicity and feasibility of CIK infusion in LT patients.

\section{Acknowledgements}

The authors woudl like to thank Dr Fang Yan (Vanderbilt University, Nashville, TN, USA) for the suggestions made during the manuscript preparation. The present study was 
supported by a grant from the National Natural Science Funds of China (no. 81402362).

\section{References}

1. Saidi RF and Hejazi Kenari SK: Liver transplantation for hepatocellular carcinoma: Past, present and future. Middle East J Dig Dis 5: 181-192, 2013.

2. Silva MF and Sherman M: Criteria for liver transplantation for HCC: What should the limits be? J Hepatol 55: 1137-1147, 2011.

3. Decaens T, Roudot-Thoraval F, Badran H, Wolf P, Durand F, Adam $\mathrm{R}$, Boillot O, Vanlemmens C, Gugenheim J, Dharancy S, et al: Impact of tumour differentiation to select patients before liver transplantation for hepatocellular carcinoma. Liver Int 31: 792-801, 2011.

4. Sapisochin G, Goldaracena N, Astete S, Laurence JM, Davidson D, Rafael E, Castells L, Sandroussi C, Bilbao I, Dopazo C, et al. Benefit of treating hepatocellular carcinoma recurrence after liver transplantation and analysis of prognostic factors for survival in a large Euro-American series. Ann Surg Oncol 22: 2286-2294, 2015.

5. Schlitt HJ, Neipp M, Weimann A, Oldhafer KJ, Schmoll E, Boeker K, Nashan B, Kubicka S, Maschek H, Tusch G, et al: Recurrence patterns of hepatocellular and fibrolamellar carcinoma after liver transplantation. J Clin Oncol 17: 324-331, 1999.

6. Ren X, Yu J, Liu H, Zhang P, An X, Zhang N and Hao X: Th1 bias in PBMC induced by multicycles of auto-CIKs infusion in malignant solid tumor patients. Cancer Biother Radiopharm 21: 22-33, 2006.

7. Li H, Wang C, Yu J, Cao S, Wei F, Zhang W, Han Y and Ren XB: Dendritic cell-activated cytokine-induced killer cells enhance the anti-tumor effect of chemotherapy on non-small cell lung cancer in patients after surgery. Cytotherapy 11: 1076-1083, 2009.

8. Liu L, Zhang W, Qi X, Li H, Yu J, Wei S, Hao X and Ren X: Randomized study of autologous cytokine-induced killer cell immunotherapy in metastatic renal carcinoma. Clin Cancer Res 18: 1751-1759, 2012

9. Li R, Wang C, Liu L, Du C, Cao S, Yu J, Wang SE, Hao X, Ren $\mathrm{X}$ and Li H: Autologous cytokine-induced killer cell immunotherapy in lung cancer: A phase II clinical study. Cancer Immunol Immunother 61: 2125-2133, 2012.

10. Nishimura R, Baker J, Beilhack A, Zeiser R, Olson JA, Sega EI, Karimi $\mathrm{M}$ and Negrin RS: In vivo trafficking and survival of cytokine-induced killer cells resulting in minimal GVHD with retention of antitumor activity. Blood 112: 2563-2574, 2008.
11. Linn YC, Lau LC and Hui KM: Generation of cytokine-induced killer cells from leukaemic samples with in vitro cytotoxicity against autologous and allogeneic leukaemic blasts. Br J Haematol 116: 78-86, 2002.

12. Takayama T, Sekine T, Makuuchi M, Yamasaki S, Kosuge T, Yamamoto J, Shimada K, Sakamoto M, Hirohashi S, Ohashi Y, et al: Adoptive immunotherapy to lower postsurgical recurrence rates of hepatocellular carcinoma: A randomised trial. Lancet 356: 802-807, 2000.

13. Hui D, Qiang L, Jian W, Ti Z and Da-Lu K: A randomized, controlled trial of postoperative adjuvant cytokine-induced killer cells immunotherapy after radical resection of hepatocellular carcinoma. Dig Liver Dis 41: 36-41, 2009.

14. Dollinger MM, Howie SE, Plevris JN, Graham AM, Hayes PC and Harrison DJ: Intrahepatic proliferation of 'naive' and 'memory' T cells during liver allograft rejection: Primary immune response within the allograft. FASEB J 12: 939-947, 1998.

15. Sangiolo D, Mesiano G, Carnevale-Schianca F, Piacibello W, Aglietta M and Cignetti A: Cytokine induced killer cells as adoptive immunotherapy strategy to augment graft versus tumor after hematopoietic cell transplantation. Expert Opin Biol Ther 9: 831-840, 2009.

16. Lowdell MW, Lamb L, Hoyle C, Velardi A and Prentice HG: Non-MHC-restricted cytotoxic cells: Their roles in the control and treatment of leukaemias. Br J Haematol 114: 11-24, 2001.

17. Kägi D, Ledermann B, Bürki K, Seiler P, Odermatt B, Olsen KJ, Podack ER, Zinkernagel RM and Hengartner H: Cytotoxicity mediated by $\mathrm{T}$ cells and natural killer cells is greatly impaired in perforin-deficient mice. Nature 369: 31-37, 1994.

18. Heusel J W, Wesselschmidt R L, Shresta S, Russell JH and Ley TJ: Cytotoxic lymphocytes require granzyme B for the rapid induction of DNA fragmentation and apoptosis in allogeneic target cells. Cell 76: 977-987, 1994.

19. Wang Y, Dai H, Li H, Lv H, Wang T, Fu X and Han W: Growth of human colorectal cancer SW1116 cells is inhibited by cytokine-induced killer cells. Clin Dev Immunol 2011: 621414, 2010.

20. Wang X, Yu W, Li H, Yu J, Zhang X, Ren X and Cao S: Can the dual-functional capability of CIK cells be used to improve antitumor effects? Cell Immunol 287: 18-22, 2014.

21. Mehta BA, Schmidt-Wolf IG, Weissman IL and Negrin RS: Two pathways of exocytosis of cytoplasmic granule contents and target cell killing by cytokine-induced $\mathrm{CD} 3{ }^{+} \mathrm{CD} 56^{+}$killer cells. Blood 86: 3493-3499, 1995. 